Running head: MENTAL CONTEXT REINSTATEMENT

\begin{abstract}
Mental context reinstatement reduces resistance to false suggestions after children have experienced a repeated event
\end{abstract}

\author{
Donna M. Jennings Kim P. Roberts \\ Wilfrid Laurier University \\ Martine B. Powell \\ Deakin University
}

Acknowledgements. This research was supported by a Large Research Grant (A7924116) to Martine Powell and Kim Roberts from the Australian Research Council and by a grant to Kim Roberts from the Social Sciences and Humanities Research Council of Canada. A portion of these data were presented at the Sixth Biennial Meeting of the Cognitive Development Society, San Antonio, TX and at the 2010 meeting of the American Psychology-Law Society (Division 41 of the American Psychological Association), Vancouver, BC. The authors are grateful to the families and children who participated in this research, and to the teachers and staff of participating schools. Special thanks to Sarah Pearse. Thank you also to Natalie Aarons, Natasha Anderson, Cady Berkel, Catherine Croft, Katrina Hodgson, Melissa McCauley, Rachel Same, and Nicole Sirrine for their assistance with data collection and coding.

Correspondence to: Kim P. Roberts, Psychology Department, Wilfrid Laurier University, 75

University Avenue West, Waterloo, ON, N2L 3C5, Canada. E-mail: kroberts@wlu.ca 


\begin{abstract}
When children allege repeated abuse, they are required to provide details about specific instances. This often results in children confusing details from different instances and so we examined whether 'mental context reinstatement' (MCR) could be used to improve children's accuracy. Children ( $N=120,6$-7-year olds) participated in 4 activities over a 2 -week period and were interviewed about the last $\left(4^{\text {th }}\right)$ time with a standard recall or mental context reinstatement interview. They were then asked questions about specific details, and some questions contained false information. When interviewed again a day later, children in the MCR condition resisted false suggestions that were consistent with the event more than false suggestions that were inconsistent; in contrast, children in the standard interview condition were equally suggestible for both false detail types and showed a 'yes bias'. The results suggest a practical way of eliciting more accurate information from child witnesses.
\end{abstract}


Mental context reinstatement reduces resistance to false suggestions after children have experienced a repeated event

Children experience a variety of repeated, routine events on a regular basis, such as swimming lessons, sports practices, and attending school or a religious institution (e.g., church, mosque). Unfortunately some children also experience child abuse or bullying, which may occur repeatedly and have routine aspects. Previous research has demonstrated that repeated event memory is qualitatively different from novel event memory (Powell \& Thomson, 1996, 1997; Roberts \& Blades, 1998; see also Roberts, 2002; and Roberts \& Powell, 2001, for reviews). For example, compared to children who experience an event just one time, children with repeated event experience are more accurate for general event details that are the same each time, but less accurate about unique details specific to individual occurrences of the event (Hudson \& Nelson, 1986; Pearse, Powell, \& Thomson, 2003; Powell \& Thomson, 1996). Thus, how often an event has been experienced can have profound effects on children's memories and children typically find it quite challenging to distinguish and discuss a single occurrence of a repeated event (Powell \& Thomson, 1997).

Children's ability to distinguish between similar events relies on their ability to make accurate temporal and source-monitoring decisions, a task which is difficult for many children. Nonetheless, when providing testimony in a forensic situation, child eyewitnesses are typically required to discuss a single instance of an event that may have happened many times (see Powell, Roberts \& Guadagno, 2007, for a review). Understanding children's capacity to discuss a particular occurrence of a repeated event and how to facilitate their ability to do so therefore has important practical implications for forensic and investigative interviews. In this study, we 
tested whether 'mental context reinstatement' enabled children to more accurately remember a single episode of a repeated event than a standard interview.

An interview that relies on open-ended prompts (e.g., tell me more) rather than optionposing or yes/no questions leads children to provide more descriptive, freely-recalled information (Lamb, Orbach, Hershkowitz, Esplin, \& Horowitz, 2007; Sternberg, Lamb, Orbach, Esplin \& Mitchell, 2001). Children also provide more accurate information when they are asked open-ended questions than when they are asked forced-choice or specific, focused questions (Hutcheson, Baxter, Telfer, \& Warden, 1995). In the case of multiple allegations from the same child, however, it is vital to develop interview procedures that help children distinguish between episodes of repeated events, in addition to the effective use of open-ended prompts.

One means by which children may be assisted in providing more accurate testimony is by interviewing them with the mental context reinstatement (MCR) technique, which is a component of the Cognitive Interview (Fisher \& Geiselman, 1992; Geiselman, 1988). The Cognitive Interview was developed to provide eyewitnesses with several mnemonic techniques to improve their memory for events (Geiselman, 1988). These mnemonic techniques include reverse recall (recalling an event from the end to the beginning), recall from another's perspective (taking the perspective of another individual present at the event and reporting how they likely would have perceived the event), complete report (interviewee is encouraged to report every detail regardless of whether they think it may be insignificant), and MCR (Fisher \& Geiselman). Not all of these techniques are appropriate for use with children, but MCR may be one aspect of the Cognitive Interview that would help children with event recall. The MCR technique encourages individuals to mentally return to a target event by thinking about, for 
example, their sensory experiences and emotions during the event, and by visualizing their surroundings and any actions they performed or saw others perform (Fisher \& Geiselman).

There is some support for using the Cognitive Interview, and specifically MCR instructions, with children. For example, when children were encouraged to mentally recreate their surroundings at the time of a to-be-remembered event while providing free recall, they provided more information overall that was also more accurate compared to reports from children interviewed with a standard, open-ended interview (McCauley \& Fisher, 1995). Although children interviewed with MCR also reported more incorrect details than those interviewed with a standard interview, overall accuracy rates were just as high given that these children provided more information in total (McCauley \& Fisher). Similar results have been found in several other empirical studies (Hayes \& Delamothe, 1997; see also Larsson \& Lamb, 2009 and Pipe, Lamb, Orbach \& Esplin, 2004, for reviews). However, some research has found that use of the Cognitive Interview increases the amount of correct information reported without a corresponding increase in incorrect information (Akehurst, Milne, \& Köhnken, 2003; Bowen \& Howie, 2002; Hammond, Wagstaff, \& Cole, 2006; Holliday, 2003a; Holliday, 2003b; Holliday \& Albon, 2004) and sometimes leads to higher overall accuracy rates (Larsson, Granhag, \& Spjut, 2003; Milne \& Bull, 2003). These findings suggest that MCR may be an effective tool in assisting children in providing more accurate reports about their memories.

While there is no existing empirical evidence specific to the use of MCR when interviewing children about repeated events, at least two studies on interviews in child abuse investigations have examined the use of MCR with children (Hershkowitz, Orbach, Lamb, Sternberg \& Horowitz, 2001, 2002). These studies found that children freely recalled more information when MCR prompts were used, compared to a standard investigative interview or 
physical context reinstatement (i.e., returning to the scene of alleged crimes). Although information provided in free recall tends to be relatively accurate (e.g., Hutcheson et al., 1995), it was not possible to determine how MCR may have affected accuracy in these studies.

The current study expands on previous research on MCR by being the first to systematically explore the effect of MCR on the accuracy of children's memory for repeated events. The goal of this study is to determine whether MCR is an appropriate and effective interview technique for use with children that have experienced similar events multiple times. More specifically, this study examines whether MCR can assist children in discussing a specific instance of a repeated experience by increasing accuracy.

\section{Source Monitoring}

Source monitoring refers to the ability to make determinations about where knowledge was obtained (Johnson, Hashtroudi, \& Lindsay, 1993). In the context of repeated events, the source of a memory refers to the particular occurrence from which a recalled detail was present. For example, if the children sat on cardboard the day they made a puzzle of a clown juggling, the source of the memory of sitting on cardboard would be the day the puzzle was of a clown juggling. Children may find it challenging to monitor the source of information they recall, making it difficult for them to distinguish which details are tied to a specific occurrence of a repeated event (see Roberts, 2002, for a review). Source monitoring decisions are made at the time individuals are attempting to recall an event; thus, reflecting on feelings and sensory information that were experienced at the time of an event may improve children's ability to recall that event accurately (Johnson et al.). The MCR technique may therefore assist children in determining whether a particular detail was present in a specific occurrence of a repeated event. 
Powell and Thomson (2003) found that when children were given a list of all possible variations of a detail from a repeated event, they were more accurate in identifying which variation was present in a particular occurrence compared to children who were not provided with a list of possibilities. It may be that having a list of variations improved children's ability to access source information about the events (Powell \& Thomson, 2003) by providing them with a cue that helped them order the instantiations temporally and, thus, distinguish between occurrences. It is generally not feasible, though, for investigative interviewers to provide children with details about events to choose from. MCR may help children, however, recall more information and therefore help children overcome confusion about which specific details occurred during a particular episode of a repeated event; MCR might allow children to generate cues that may enable them to differentiate between occurrences.

\section{The Current Study}

If MCR indeed aids children in monitoring source information from their memories, they should be more accurate when asked to discuss a specific occurrence of a repeated event. In the current study, then, children participated in four repeated events consisting of 16 activities that varied during each occurrence. At a fifth biasing interview session, which took place after a oneor four-week delay, children provided a free narrative about the final session of the activities, using either standard interview prompts or MCR instructions. The children were then asked 16 specific questions about the activities. Eight of the specific questions were about accurate (true)

details from the target occurrence, while eight of them were about inaccurate (false) details. The false details were either consistent with the theme of the activity or inconsistent with the theme of the activity. For example, if the child sat on a garbage bag, a false-consistent question was "Did you sit on newspaper?" (i.e., something flat on the floor) while a false-inconsistent question 
was "Did you sit on a wooden chair?" (i.e., something raised above the floor). The following day, at a final memory interview session, children answered 32 yes/no questions about both the true and false (suggested) details.

Roberts and Powell (2006) found that children were more resistant to suggestion (i.e., were less likely to accept incorrect information presented by an interviewer) when the suggested information was inconsistent with the theme of an activity, than when the suggested information was consistent with the theme. We were particularly interested, then, in testing whether MCR would reduce errors made by (inaccurately) accepting false information that was consistent with the event (given that these errors are more numerous than accepting false information that is inconsistent with the event). Thus, while children in the MCR condition are expected to be more accurate for both false question types compared to the standard interview condition, the MCR interview should help children to be particularly resistant to false-consistent suggestions.

The methodology of this study also allows for the comparison of MCR and a standard interview at two different delays. This is important since long retention intervals have been shown to have a negative impact on children's event recall (Powell \& Thomson, 1997). Therefore, children in the one-week delay condition are expected to be more accurate than are children in the four-week delay condition. However, the use of the MCR technique may provide contextual cues that will improve children's recall after a delay. Thus children in the MCR condition should be more accurate at both delays compared to the standard condition, although the difference between the two groups will be greatest at the one-week delay. 


\section{Method}

Design

The design of this study comprised a 2 (Interview Condition: MCR or Standard) x 2 (Delay: 1- or 4-week) between-subjects experimental design. Children participated in four activities over a 2-week period, were given a biasing interview in which false suggestions (some consistent and some inconsistent with the theme of the events) were presented, and then were given a memory interview. Responses at the memory interview are the dependent variables.

\section{Participants}

A total of $1206-7$-year-old $(M=79.98$ months, $S D=4.00)$ children participated, and were recruited from schools in the Melbourne, Australia area. An equal number of males and females participated. Parents gave informed consent if they were willing for their child to participate, and verbal assent was obtained from the children both before the events and prior to the interview sessions.

\section{Materials}

Each event in the series consisted of 16 activities (items) that followed the same activity script; however, specific details (instantiations) varied each time. For example, the children engaged in a warm-up activity each day, but the actual activity they did to warm up was different each time. A complete list of the items and all their instantiations is included in the Appendix. Furthermore, in order to ensure that children did not confuse items in the events with items they have encountered elsewhere, the items used in the current study were designed specifically for the study, and are not commercially available. The materials have been successfully used in previous studies (e.g., Powell, Roberts, Ceci, \& Hembrooke, 1999; Powell, Roberts, Thomson, \& Ceci, 2007; Roberts \& Powell, 2007). 


\section{Procedure}

Events

All participants took part in four 30-minute repeated-event sessions within a two week period. A trained research assistant led all children in the activities, which were referred to as the "Deakin Activities" on each occasion. Each event session included 16 activities that varied at each occurrence. The possible sets of activities were divided into groups of four, and which four sets were presented to each group was counterbalanced. For example, if one group participated in sets A, B, C and E, another group participated in E, D, A, and B (see the Appendix for a list of the activities and their instantiations). The fourth event session (the target session for the interviews) included a 'tag' to serve as an identifier of the target session during the interview. The tag was either a new leader, a prominent necklace, or a badge. The tags were present only in the last occurrence. Children participated in the activity sessions in groups, however they were interviewed individually.

\section{The Biasing Interview}

After either a one- or four-week delay, children participated in an interview during which they first provided a brief narrative elicited with either standard open-ended prompts or MCR instructions, and were then asked 16 specific questions about the final occurrence of the events. Interviews were approximately 25 to 30 minutes in length and were conducted by research assistants (RAs) other than the RAs that led the events. Children were randomly assigned to one of two interview conditions, receiving either standard, open-ended prompts or MCR instructions, with the constraint that there be an equal number of participants in each condition, and gender was balanced. In the standard interview condition, the interview began with an introductory phase in which the interviewer asked the child whether they remembered participating in the 
Deakin Activities, and instructing the child that the interviewer wanted to hear about the session where they had a new leader or wore the necklace or badge (depending on the individual child's condition). The substantive phase of the interview followed, with an initial prompt asking the child to tell the interviewer everything s/he could remember about that event session. Throughout the interview, further details were elicited using open-ended prompts such as "What happened next?" and "Tell me what else you remember."

The introductory phase of the MCR interview began with the interviewer asking the child whether they remembered participating in the Deakin Activities, and drawing the child's attention to the target session. Children were given instructions aimed to help them mentally recreate the session dependent on their tag condition. Children in the "New leader" group were asked to think about and describe what the new leader looked like, what she wore, how it felt to have a new leader and whether the new leader did a good job of leading the activities. Children in the "Necklace/Badge" group were asked to think about and describe what the necklace or badge looked like, how they felt when they wore something new that time, and whether they liked the Deakin Activities that time. As with the standard interview, the substantive phase of the interview of the MCR interview began by asking the child to tell the interviewer everything s/he could remember about that event session, with open-ended prompts to elicit further information.

After the free narrative, the RA told the child she had some more questions to ask, and instructed the child that s/he should answer them as well as s/he could even if the information had already been discussed. Each child was then asked 16 specific questions about the activities; one question for each detail in the final event session. Eight of the questions referred to accurate (true) details about the activities, for example, "What colour was the garbage bag you sat on?" The other four questions referred to inaccurate (false) details about the activities. Two of the 
false details were consistent with the activities (e.g., "What color was the newspaper you sat on the last day?") and the other two false details were inconsistent with the activities (e.g., "What color was the wooden chair you sat on?"). The questions were asked in a random order, and the assignment of details to true or false questions was counterbalanced. The questions containing true information was included to balance the interview (otherwise children would realize they were being misled constantly) and are not included in the analyses.

\section{The Memory Interview}

One day after the biasing interview, the children received a final memory interview from the same RA that conducted the previous interview. The RA told the child that she had lost their answers from the previous day, and that she was therefore going to ask some questions about the Deakin Activities again. Children were asked a total of 32 yes/no questions related to the 16 details from the biasing interview. Two sets of 16 yes/no questions were created, such that in total, there were 16 true questions, eight false-consistent and eight false-inconsistent. This allowed for counterbalancing of whether the yes/no question about a particular detail was probed first in a consistent or inconsistent manner with the way the detail was probed at the biasing interview (see Table 1). Thus, if a particular detail was described inaccurately (for example, false-consistent) at the biasing interview, in one set of sixteen questions at the memory interview it was true, and in the other set of questions it was false-consistent. Which set of 16 questions was asked first was counterbalanced across children. Children's responses were coded as correct when the child responded yes to true details and no to false details. Interrater agreement was at least $98 \%$ across response types. 


\section{Results}

An alpha level of .05 was used to determine significance for all results in this study, unless otherwise noted below. All data are responses to the yes/no questions at the final $\left(2^{\text {nd }}\right)$ interview. Inspection of Table 2 shows that the means from children in the MCR condition were higher in 7 of the 8 comparisons than those in the standard interview condition. We now present inferential analyses on these data. Note that the data refers to responses about items that were inaccurately described at the biasing interview as we were specifically interested in whether MCR would reduce errors about false-consistent details; at the memory interview, however, these details were described both accurately (true) and inaccurately (false).

A 2 (Interview: MCR vs. Standard) x 2 (Delay: 1- or 4-weeks) x 2 (Biasing Interview Suggestion: false consistent or false inconsistent) x 2 (Memory Interview Detail: true or false) analysis of variance (ANOVA) was conducted for all correct responses (i.e., yes responses to true details and no responses to false details), with biasing interview suggestion and detail being within-subjects. Because false details were asked in the same format at both the biasing interview and the memory interview (i.e., false-consistent items were false-consistent at both interviews) the detail variable had two levels (true and false). See Table 2 for the means and standard deviations for all items described inaccurately at the biasing interview.

There was a main effect of detail $\left(F_{(1,116)}=9.61, p=.002, \eta_{p}{ }^{2}=.08\right)$, as children were more accurate when asked about the true version of the details $(M=2.96, S E=.07)$ than the false version $(M=2.60, S E=.10)$. There was also a main effect of delay, as children were more accurate at the one-week delay $(M=3.00, S E=.09)$ than they were at the four-week delay $(M=$ 2.57, $S E=.09)\left(F_{(1,116)}=10.72, p=.001, \eta_{p}^{2}=.09\right)$. 
Both delay and detail approached significant interactions with the interview variable [detail and interview $\left(F_{(1,116)}=3.67, p=.06, \eta_{p}{ }^{2}=.03\right)$; biasing interview suggestion, interview and delay $\left.\left(F_{(1,116)}=3.67, p=.06, \eta_{p}^{2}=.03\right)\right]$, but these results were qualified by a significant interaction of interview, delay, biasing interview suggestion and detail $\left(F_{(1,116)}=3.96, p=.05\right.$, $\left.\eta_{p}{ }^{2}=.03\right)$. Because there was an effect of delay, the analyses were split by this variable in order to aid in interpreting the four-way interaction. Thus, a 2 (Interview: MCR vs. Standard) x 2 (Biasing Interview Suggestion: false consistent or false inconsistent) x 2 (Detail: true or false) ANOVA was run separately for the one- and four-week delays.

One-week delay. Interview condition interacted with both biasing interview suggestion $\left(F_{(1,58)}=5.30, p=.03, \eta_{p}{ }^{2}=.08\right)$ and detail $\left(F_{(1,58)}=6.40, p=.01, \eta_{p}{ }^{2}=.10\right)$. The interaction between biasing suggestion and interview occurred because children who received the MCR instructions were more accurate for false-consistent $(M=6.39, S D=1.31)$ versus falseinconsistent items $(M=5.71, S D=1.40), t_{(31)}=-2.33, p=.03$, while there was no difference between the two types of false items for children in the standard recall interview $\left(t_{(30)}=1.02, p=\right.$ .32) (as was predicted). There was no difference between MCR instructions and the standard interview for false inconsistent details $\left(t_{(58)}=1.01, p=.32\right)$, however there was a nonsignificant trend toward a difference between the two groups for false consistent items $\left(t_{(58)}=-1.66, p=\right.$ .10) because children in the MCR condition were more accurate than those in the standard interview condition.

Although there was a main effect of detail, $F_{(1,58)}=6.94, p=.01, \eta_{p}{ }^{2}=.10$, (because children were more accurate for true items $[M=3.20, S E=.08]$ than they were for false items $[M=2.80, S E=.13])$, the Detail $\mathrm{x}$ Interview interaction showed that children in the standard recall condition were more accurate $(M=6.72, S D=1.22)$ than children in the MCR condition 
$\left.(M=6.06, S D=2.33), t_{(58)}=1.97, p=.05\right)$ when recalling details that were true at the memory interview. In contrast, there was no significant difference between the groups on items that were false although there was a trend such that children in the MCR condition were more accurate $(M$ $=6.03, S D=1.70)$ than those in the control condition $(M=5.14, S D=2.33), t_{(58)}=-1.71, p=$ .09 .

It was not predicted that children in the standard recall interview would provide a greater number of accurate responses to the items that were accurately described at the memory interview. However, such a result could occur if these children had a 'yes bias'. A 'yes' response to a falsely-described detail would be incorrect, but correct for an accurately described detail. Thus, higher scores would be expected in response to questions about true items than false items, and examination of the means in Table 2 shows exactly this pattern - children in the standard recall condition were more accurate for true than false details showing that they often said yes regardless of the accuracy of the item in the question. In contrast, children in the MCR condition did not show this pattern; their superior rejection of false-consistent details rules out a 'yes' bias.

Four-week delay. In contrast to reports at the one-week delay, there were no effects or interactions with the interview condition. There was a marginally significant interaction of biasing interview suggestion and detail, $F_{(1,58)}=3.69, p=.06, \eta_{p}{ }^{2}=.06$, because children were more accurate for details that were false inconsistent at the biasing interview and true at the memory interview $(M=2.83, S D=1.08)$ than they were for items that were false inconsistent at both interviews $(M=2.33, S D=1.34), t_{(59)}=-2.44, p=.02$. Children were equally as suggestible for false-consistent details regardless of whether they were accurately $(M=2.62, S D$ $=1.06)$ or inaccurately described at the memory interview $(M=2.48, S D=1.28), t_{(59)}=-.69, p$ $=.49$. 
Thus overall, children were more accurate for true details than false details, and more accurate at a one-week delay compared to a four-week delay. However, the effects of MCR varied depending on the length of the delay. Specifically, children who received MCR instructions resisted false suggestions that were consistent with the event theme more than falseinconsistent details, as expected, but only at the one-week delay.

\section{Discussion}

After repeated event experience, children may have difficulty distinguishing between occurrences of the events due to the challenges associated with remembering the specific source of their memories (i.e., which occurrence specific activities took place in; Roberts, 2002) and difficulty with remembering when specific activities occurred (temporal monitoring; Powell \& Thomson, 1997, 2003). Nonetheless, children are often expected to discuss one or two separate instances of a repeated event when providing testimony in forensic investigations (see Powell et al., 2007, for a review). Identifying interview techniques that enable children to more accurately discuss a single episode of a repeated experience is therefore critical. The current study examined the use of MCR instructions as a means to help children determine whether a particular detail was a part of a specific instance of a repeated event. As children can incorporate false information that is nevertheless consistent with the theme of the events, we aimed to reduce the number of times children reported these false details as if they actually happened.

At the one-week delay, children who received MCR instructions were more accurate at rejecting false suggestions for items that were consistent with the theme versus false suggestions that were inconsistent with the theme. Children interviewed with a standard open-ended interview did not show such a reduction in errors. The finding that MCR instructions helps children be more accurate for false consistent items is especially noteworthy because children 
tend to find it particularly difficult to resist suggestions that are consistent with the event (Connolly \& Price, 2006; Roberts \& Powell, 2006), and because investigators may accept false, but consistent, reports as true because they sound plausible. It is also important to note that while MCR instructions did not help children resist false inconsistent suggestions, it also did not provide a disadvantage in resisting such suggestions compared to standard interview prompts. MCR may therefore provide a valuable tool in helping children resistant inaccurate but consistent false suggestions, without compromising their ability to resist false inconsistent suggestions.

Children were more accurate overall when the true (versus the false) version of items was probed at the memory interview. At the one-week delay, children in the standard interview condition were more accurate for details that were true at the memory interview than were children in the MCR condition. This result was surprising and there are two possible explanations. The first is that the process of mentally recreating the target event may have helped children recall more 'deeply' leading them to recall more information about the event. This could increase the chances that sources were confused (i.e., MCR may help children with content recall but not source monitoring). Another possibility is that children in the Standard Interview condition were not actually more accurate; their higher scores reflect a 'yes bias'. That is, they were prone to say 'yes' to all of the questions which would mean higher scores on questions where the correct answer was 'yes' (i.e., questions about true details). Thus, the effects of MCR could be to reduce yes biases in interviews, which is in itself a worthy goal.

There were few effects of MCR at the four-week delay. It may be that the memory trace for the target event had decayed to the point that children had difficulty mentally recreating the event, or at least that mentally recreating the event did not provide any more information than 
could be retrieved using standard interview prompts. However, because all children were less accurate at the long delay, this finding also replicates previous research that has demonstrated that, as the retention interval increases, children's overall recall of repeated events decreases and that their ability to recall details specific to a particular episode declines (Powell $\&$ Thomson, 1997). It is especially vital in forensic settings to talk to children as soon as possible after an alleged incident as the accuracy and completeness of children's reports has particularly important implications.

Overall, the findings of this study suggest that MCR instructions may help children resist suggestions that are false but consistent with the events they have experienced. Further studies examining the use of MCR in reducing inaccuracies should be conducted to find ways of enhancing children's testimony at long, as well as short, delays. For example, testing whether MCR can be used to enhance free narratives is the next logical step now that we have seen that MCR has an effect on children's memories for repeated events. Another important consideration is whether differences in the effectiveness of MCR compared to a standard interview vary developmentally. Although some previous research suggest that MCR may not be beneficial for 6-year-olds (e.g., Dietze \& Thomson, 1993), the current study suggests that MCR may indeed be helpful for this age group. Further, two field studies by Hershkowitz, Orbach, Lamb, Sternberg and Horowitz $(2001,2002)$ found that, compared to a standard investigative interview or physical context reinstatement, children as young as 4-years-old provided more information in the free recall phase of interviews when MCR was used. More research is therefore needed to determine whether MCR is a useful technique for interviewing younger children about repeated events. 
In sum, while MCR is effective when children recall a one-time event, this is the first study to show that MCR has a positive effect on children's memory of repeated events. The results show that young children (aged 6-7 in this study) have information available that can be used to determine which details go with which specific incidents. Given that incorporating MCR into investigative interviews of children is an easy technique that does not take considerably more time than standard recall interviewing, the benefits of MCR are clear. 


\section{References}

Akehurst, L., Milne, R., \& Köhnken, G. (2003). The effects of children's age and delay on recall in a cognitive or structured interview. Psychology, Crime \& Law, 9, 97-107.

Bowen, C. J., \& Howie, P. M. (2002). Context and cue cards in young children's testimony: A comparison of brief narrative elaboration and context reinstatement. Journal of Applied Psychology, 87, 1077-1085.

Connolly, D. A., Price, H. L. (2006). Children's suggestibility for an instance of a repeated event versus a unique event: The effect of degree of association between variable details. Journal of Experimental Child Psychology, 93, 207-223.

Dietze, P. M., \& Thomson, D. M. (1993). Mental reinstatement of context: A technique for interviewing child witnesses. Applied Cognitive Psychology, 7, 97-108.

Fisher, R. P., \& Geiselman, R. E. (1992). Memory-enhancing techniques for investigative interviewing: The Cognitive Interview. Springfield, IL: Thomas.

Geiselman, R. E. (1988). Improving eyewitness memory through mental reinstatement of context. In G. M. Davies and D. M. Thomson (Eds), Memory in context: Context in memory (pp. 245-266). Chichester: Wiley.

Hammond, L., Wagstaff, G. F., \& Cole, J. (2006). Facilitating eyewitness memory in adults and children with context reinstatement and focused meditation. Journal of Investigative Psychology and Offender Profiling, 3, 117-130.

Hayes, B. K., \& Delamothe, K. (1997). Cognitive interviewing procedures and suggestibility in children's recall. Journal of Applied Psychology, 82, 562-577. 
Hershkowitz, I., Orbach, Y., Lamb, M. E., Sternberg, K. J., \& Horowitz, D. (2002). A comparison of mental and physical context reinstatement in forensic interviews with alleged victims of sexual abuse. Applied Cognitive Psychology, 16, 429-441.

Hershkowitz, I., Orbach, Y., Lamb, M. E., Sternberg, K. J., \& Horowitz, D. (2001). The effects of mental context reinstatement on children's accounts of sexual abuse. Applied Cognitive Psychology, 15, 235-248.

Holliday, R. E. (2003a). The effect of a prior cognitive interview on children's acceptance of misinformation. Applied Cognitive Psychology, 17, 443-457.

Holliday, R. E. (2003b). Reducing misinformation effects in children with cognitive interviews: Dissociating recollection and familiarity. Child Development, 74, 728-751.

Holliday, R. E., \& Albon, A. J. (2004). Minimising misinformation effects in young children with cognitive interview mnemonics. Applied Cognitive Psychology, 18, 263-281.

Hudson, J., \& Nelson, K. (1986). Repeated encounters of a similar kind: Effects of familiarity on children's autobiographic memory. Cognitive Development, 1, 253-271.

Hutcheson, G. D., Baxter, J. S., Telfer, K., \& Warden, D. (1995). Child witness statement quality: Question type and errors of omission. Law and Human Behavior, 19, 641-648.

Johnson, M. K., Hashtroudi, S., \& Lindsay, D. S. (1993). Source monitoring. Psychological Bulletin, 114, 3-28.

Lamb, M. E., Orbach, Y., Hershkowitz, I., Esplin, P. W., \& Horowitz, D. (2007). A structured interview protocol improves the quality and informativeness of investigative interviews with children: A review of research using the NICHD Investigative Interview Protocol. Child Abuse \& Neglect, 31, 1201-1231. 
Larsson, A. S., Granhag, P. A., \& Spjut, E. (2003). Children's recall and the cognitive interview: Do the positive effects hold over time? Applied Cognitive Psychology, 17, 203-214.

Larsson, A. S., \& Lamb, M. E. (2009). Making the most of information-gathering interviews with children. Infant and Child Development, 18, 1-16.

McCauley, M. R., \& Fisher, R. P. (1995). Facilitating children's eyewitness recall with the revised cognitive interview. Journal of Applied Psychology, 80, 510-516.

Memon, A., \& Bull, R. (1991). The cognitive interview: Its origins, empirical support, evaluation and practical implications. Journal of Community \& Applied Social Psychology, 1, 291307.

Milne, R., \& Bull, R. (2003). Does the cognitive interview help children to resist the effects of suggestive questioning? Legal and Criminological Psychology, 8, 21-38.

Pearse, S. L., Powell, M. B., \& Thomson, D. M. (2003). The effect of contextual cues on children's ability to remember an occurrence of a repeated event. Legal and Criminological Psychology, 8, 39-50.

Pipe, M., Lamb, M. E., Orbach, Y., \& Esplin, P. W. (2004). Recent research on children's testimony about experience and witnessed events. Developmental Review, 24, 440-468.

Powell, M., Roberts, K., \& Guadagno, B. (2007). Particularisation of child abuse offences: Common problems when questioning child witnesses. Journal of the Institute of Criminology, 19, 64-74.

Powell, M. B., Roberts, K. P., Ceci, S. J., \& Hembrooke, H. H. (1999). The effects of repeated experience on children's suggestibility. Developmental Psychology, 35, 1462-1477. 
Powell, M. B., Roberts, K. P. Thomson, D. M. \& Ceci, S. J. (2007). The impact of experience versus non-experienced suggestions on children's recall of repeated events. Applied Cognitive Psychology, 21, 649-667.

Powell, M. B., \& Thomson, D. M. (1996). Children's memory of an occurrence of a repeated event: Effects of age, repetition, and retention interval across three question types. Child Development, 67, 1988-2004.

Powell, M. B., \& Thomson, D. M. (1997). Contrasting memory for temporal-source and memory for content in children's discrimination of repeated events. Applied Cognitive Psychology, 11, 339-360.

Powell, M. B., \& Thomson, D. M. (2003). Improving children's recall of an occurrence of a repeated event: Is it a matter of helping them to generate options? Law and Human Behaviour, 27, 365-384.

Roberts, K. P. (2002). Children's ability to distinguish between memories from multiple sources: Implications for the quality and accuracy of eyewitness statements. Developmental Review, 22, 403-435.

Roberts, K. P., \& Blades, M. (1998). The effects of interacting in repeated events on children's eyewitness memory and source monitoring. Applied Cognitive Psychology, 12, 489-503.

Roberts, K. P., \& Powell, M. B. (2007). The roles of prior experience and the timing of misinformation presentation on young children' event memories. Child Development, 78, 1137-1152.

Roberts, K. P., \& Powell, M. B. (2006). The consistency of false suggestions moderates children's reports of a single instance of a repeated event: Predicting increases and decreases in suggestibility. Journal of Experimental Child Psychology, 94, 68-89. 
Roberts, K. P., \& Powell, M. B. (2001). Describing individual incidents of sexual abuse: A review of research on the effects of multiple sources of information on children's reports. Child Abuse \& Neglect, 25, 1643-1659.

Sternberg, K. J., Lamb, M. E., Orbach, Y., Esplin, P. W., \& Mitchell, S. (2001). Use of a structured investigative protocol enhances young children's responses to free-recall prompts in the course of forensic interviews. Journal of Applied Psychology, 86, 9971005. 


\section{Appendix}

All possible instantiations of items included in the Deakin Activities.

\begin{tabular}{|c|c|c|c|c|c|c|c|}
\hline No. & Item & $\mathbf{A}$ & B & $\mathbf{C}$ & D & $\mathbf{E}$ & $\mathbf{F}$ \\
\hline 1 & Children's seat & Cardboard & $\begin{array}{l}\text { Rubber } \\
\text { mat }\end{array}$ & $\begin{array}{l}\text { Garbage } \\
\text { bag }\end{array}$ & $\begin{array}{l}\text { White } \\
\text { sheet }\end{array}$ & Newspaper & Pillow \\
\hline 2 & Cloak of leader & Red & Yellow & White & Blue & Green & Black \\
\hline 3 & Koala's name & Boo & Kip & Pop & Stan & Jo & Lee \\
\hline 4 & Noisy animal & Kangaroo & Goanna & Kookaburra & Dingo & Wombat & Possum \\
\hline 5 & $\begin{array}{l}\text { Warm-up } \\
\text { activity }\end{array}$ & Run & $\begin{array}{l}\text { Wiggle } \\
\text { fingers }\end{array}$ & Touch toes & Jump & Dance & Sit-ups \\
\hline 6 & Source of story & $\begin{array}{l}\text { Garbage } \\
\text { bin at } \\
\text { Deakin } \\
\text { University }\end{array}$ & $\begin{array}{l}\text { Leader } \\
\text { wrote on } \\
\text { Deakin } \\
\text { University } \\
\text { Instruction }\end{array}$ & $\begin{array}{l}\text { Posted by } \\
\text { Deakin } \\
\text { University } \\
\text { person }\end{array}$ & $\begin{array}{l}\text { Library at } \\
\text { Deakin } \\
\text { University }\end{array}$ & $\begin{array}{l}\text { Present } \\
\text { under tree } \\
\text { from } \\
\text { Deakin } \\
\text { University } \\
\text { friend }\end{array}$ & $\begin{array}{l}\text { Deakin } \\
\text { University } \\
\text { bookshop }\end{array}$ \\
\hline 7 & Content of story & Horse & $\begin{array}{l}\text { Lucky } \\
\text { rabbit }\end{array}$ & Fly & Supercat & Elephant & Worm \\
\hline 8 & $\begin{array}{l}\text { Child who holds } \\
\text { up pictures }\end{array}$ & Child A & Child B & Child C & Child D & Child E & Child F \\
\hline 9 & $\begin{array}{l}\text { Utensil to note } \\
\text { who child is }\end{array}$ & Pencil & Crayon & Chalk & Marker & Lipstick & Paint \\
\hline 10 & Puzzle & $\begin{array}{l}\text { Waving a } \\
\text { wand }\end{array}$ & $\begin{array}{l}\text { Playing } \\
\text { guitar }\end{array}$ & $\begin{array}{l}\text { Balancing } \\
\text { balls }\end{array}$ & Juggling & $\begin{array}{l}\text { Walking } \\
\text { on } \\
\text { tightrope }\end{array}$ & Bicycling \\
\hline 11 & $\begin{array}{l}\text { Music/Scene for } \\
\text { resting }\end{array}$ & Beach & Kites & Birds & Rain & Park & Circus \\
\hline 12 & $\begin{array}{l}\text { Part of body is } \\
\text { relaxed }\end{array}$ & Legs & Nose & Stomach & Arms & Ears & Chin \\
\hline 13 & $\begin{array}{l}\text { Method of } \\
\text { getting } \\
\text { refreshed }\end{array}$ & Baby wipe & Lip gloss & $\begin{array}{l}\text { Hand } \\
\text { cream }\end{array}$ & Face spray & Cool drink & Ice pack \\
\hline 14 & $\begin{array}{l}\text { Theme of } \\
\text { sticker }\end{array}$ & Rocket & Rainbow & Star & Flag & Sun & Aeroplane \\
\hline 15 & $\begin{array}{l}\text { Container with } \\
\text { stickers }\end{array}$ & Box & Purse & Envelope & Jar & Basket & Metal tin \\
\hline 16 & Next stop & To movie & $\begin{array}{l}\text { Walking a } \\
\text { dog }\end{array}$ & $\begin{array}{l}\text { Visiting } \\
\text { friend in } \\
\text { hospital }\end{array}$ & $\begin{array}{l}\text { Birthday } \\
\text { party }\end{array}$ & $\begin{array}{l}\text { Going on } \\
\text { holiday }\end{array}$ & shop \\
\hline
\end{tabular}


Table 1.

Possible Combination of Description of Detail at Biasing and Memory Interviews

Description of Detail in Question at Biasing Description of Detail in Question at Memory Interview Interview

\begin{tabular}{ll}
\hline Four false-consistent & Two true \\
& Two false-consistent \\
Four false-inconsistent & Two true \\
& Two false-inconsistent \\
Eight true* & Four true* \\
& Two false-consistent* \\
& Two false-inconsistent* \\
\hline
\end{tabular}

Notes. $*=$ Filler items that were not analysed. 
Table 2.

Mean Accuracy Rates for Responses at Memory Interview to Items Described Inaccurately at Biasing Interview

\begin{tabular}{|c|c|c|c|c|}
\hline \multirow{2}{*}{$\begin{array}{l}\text { Description at Biasing Interview } \\
\text { Description at Memory Interview }\end{array}$} & \multicolumn{2}{|c|}{ False Consistent } & \multicolumn{2}{|c|}{ False Inconsistent } \\
\hline & True & False Consistent & True & False Inconsistent \\
\hline \multicolumn{5}{|l|}{ One Week Delay } \\
\hline Control $(n=29)$ & $3.21(.90)$ & $2.55(1.18)$ & $3.52(.74)$ & $2.59(1.40)$ \\
\hline $\operatorname{MCR}(n=31)$ & $3.26(.82)$ & $3.13(.92)$ & $2.81(1.01)$ & $2.90(1.01)$ \\
\hline Total $(N=60)$ & $3.23(.85)$ & $2.85(1.09)$ & $3.15(.95)$ & $2.75(1.22)$ \\
\hline \multicolumn{5}{|l|}{ Four Week Delay } \\
\hline Control $(n=31)$ & $2.68(1.11)$ & $2.35(1.25)$ & $2.71(1.04)$ & $2.29(1.51)$ \\
\hline $\operatorname{MCR}(n=29)$ & $2.55(1.02)$ & $2.62(1.32)$ & $2.97(1.12)$ & $2.38(1.15)$ \\
\hline Total $(N=60)$ & $2.62(1.06)$ & $2.48(1.28)$ & $2.83(1.08)$ & $2.33(1.34)$ \\
\hline
\end{tabular}

Note: Standard deviations in parenthesis. Maximum score $=4$. 